\title{
A 3D Direct Vehicle-Pavement Coupling Dynamic Model and Its Application on Analysis of Asphalt Pavement Dynamic Response
}

\author{
Peng Cao, ${ }^{1}$ Changjun Zhou, ${ }^{2}$ Decheng Feng, ${ }^{1}$ Youxuan Zhao, ${ }^{3}$ and Baoshan Huang ${ }^{2}$ \\ ${ }^{1}$ School of Transportation Science and Engineering, Harbin Institute of Technology, Harbin 150090, China \\ ${ }^{2}$ Department of Civil and Environmental Engineering, University of Tennessee, Knoxville, TN 37996-2010, USA \\ ${ }^{3}$ School of Civil Engineering, Southwest Jiaotong University, Chengdu 610031, China \\ Correspondence should be addressed to Peng Cao; caopeng518888@126.com
}

Received 29 June 2013; Accepted 9 July 2013

Academic Editor: Song Cen

Copyright (c) 2013 Peng Cao et al. This is an open access article distributed under the Creative Commons Attribution License, which permits unrestricted use, distribution, and reproduction in any medium, provided the original work is properly cited.

\begin{abstract}
Currently dynamic response of the pavement structure is widely studied in pavement engineering. A 3D direct vehicle-pavement coupling dynamic model was developed to describe the pavement dynamic responses in this paper. The moving vehicle was simplified as spring-dashpot components, and the pavement structure was simulated using three-dimension finite element model. Based on Newton iteration and central difference integration algorithm, the static and dynamic coupling reactions between the pavement structure and vehicle were considered using finite element platform ABAQUS. The numerical results fit analytic results very well in static analysis and fit experiment results in dynamic analysis well too. The simulated results indicate that the dynamic pavement surface deflection is much higher than the situation in static analysis, due to the overlapping effect. This phenomenon enhances when vehicle speed increases. A discontinuous zone of shear stress was observed on the base surface between the location under moving load and the location the moving load just passed. It was also found that the vertical fluctuation exists on the vehicle even if there is no roughness on the pavement surface. In general, the developed 3-D direct vehicle-pavement coupling dynamic model was validated to be effective on evaluating pavement dynamic responses.
\end{abstract}

\section{Introduction}

The service level of asphalt pavement is highly dependent on its performance under dynamic loads. Linear elastic theory with static loads was adopted in the early pavement design methodologies corresponding to the small traffic volume, low speed, and relative light load. However, due to the wide use of heavy truck and the increase of traffic volume and speed in past decades, these methodologies have been challenged.

Pavement dynamic responses may be larger than static responses and exacerbate pavement distresses. Therefore, when pavement dynamic responses are considered, the reliability and durability of pavement structure would be sufficiently evaluated. The close relationship exists between pavement permanent deformation and dynamic responses [1]. The impact of dynamic loads on pavement was studied in the middle of 20th century based on analytic theories restrained from the limited computing technology. Cole and
Huth [2] and Baron et al. [3] proposed the analytic solution for pavement dynamic responses under a moving load in a symmetric half-space. Kenney [4] simplified pavement as a beam in a steady-station vibration on the Winkler foundation. Hanazato et al. [5] studied the traffic-induced ground vibration decreasing phenomenon due to damping force based on elastic theory. Jones et al. [6, 7] utilized Fourier transform to solve pavement dynamic responses in time history and developed analytical solutions for pavement responses under moving loads with rectangular shapes. Since then, Fourier transform was utilized to describe the viscoelastic characteristics of asphalt layers, and to analyze pavement dynamic and vibration behaviors [8-11]. However, these previous analytical solutions were based on the elastic or viscoelastic assumptions for asphalt pavement materials and only for specific shapes of load contact areas, which makes these oversimplified models highly different from field conditions [12-14]. Additionally, the ignorance of vehicle 
inertia, the vehicle-pavement coupling effect, and/or the shell model $[15,16]$ for pavement structure makes analytical solutions inaccurate.

With the development of computational mechanics, the finite element method and the boundary element method broke the limitations of boundary conditions and load types in analytical methods. Zaghloul and White [17] analyzed dynamic responses of pavement structure with ABAQUS software and validated it with test results. Alabi [18] studied dynamic responses of pavement structure under moving concentrated force through numerical integration and conducted sensitivity analysis on load speed. Saad et al. [19], Huang et al. [20], and Huang et al. [9] described permanent deformation of asphalt pavements in three-dimensional finite element models, respectively. Finite element methods, although widely used, usually describe dynamic behaviors of pavement structure in indirect coupling methods. Generally there are two indirect coupling methods. One is to lay measured load data onto pavements, and the other is to calculate vehicle dynamic loads and set them onto pavements as load boundary conditions. These indirect coupling methods ignore the vehicle-pavement coupling effect.

\section{Objectives and Scope}

The objective of this paper was to develop a direct vehiclepavement coupling dynamic model to analyze the asphalt pavement dynamic behavior and to demonstrate its advantages over traditional static models and indirect vehiclepavement models on describing asphalt pavement dynamic responses.

One static model and two direct vehicle-pavement coupling dynamic models were developed on a typical asphalt pavement structure to evaluate pavement responses. The pavement responses from the static model were compared with analytical solutions, and those from dynamic models were compared with measured data. Also the vehicle behavior in the vehicle-pavement coupling system was also analyzed.

\section{Inputs}

3.1. Pavement Structure. A typical asphalt pavement structure with semirigid base [21] in China was selected, as shown in Figure 1. This kind of asphalt pavement usually has a cement stabilized base underneath asphalt layers.

3.2. Materials. Due to its viscoelastic characteristics, the behavior of asphalt binder is highly dependent on load duration, the environmental temperature, and especially the load frequency. Dynamic modulus is a basic parameter to describe the dynamic characteristic of asphalt concrete. Typical values of mechanical parameters for the pavement section were selected [22] and shown in Table 1. Asphalt layers adopted the same values due to their similar characteristics.

3.3. Load. Tires, as directly contacted with pavement surface, have factors such as contact shape, contact area, and pressure distribution, which significantly affect pavement dynamic

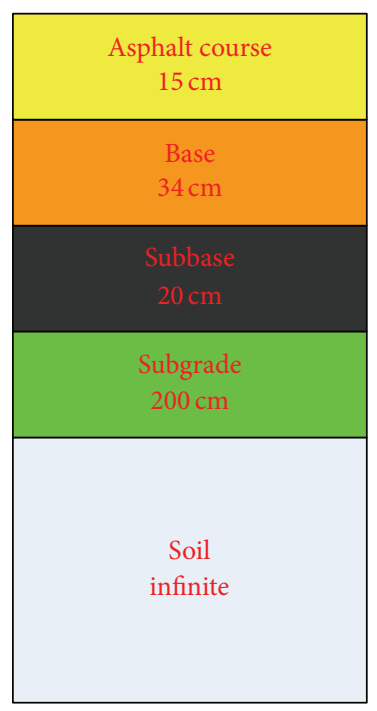

Figure 1: Pavement structure sketch.

TABLE 1: Pavement structure and material properties.

\begin{tabular}{lcccc}
\hline Layer & $\begin{array}{c}\text { Thickness } \\
(\mathrm{cm})\end{array}$ & $\begin{array}{c}\text { Compressive } \\
\text { modulus } \\
(\mathrm{MPa})\end{array}$ & $\begin{array}{c}\text { Dynamic } \\
\text { modulus } \\
(\mathrm{MPa})\end{array}$ & $\begin{array}{c}\text { Poison's } \\
\text { ratio }\end{array}$ \\
\hline Asphalt course & 15 & 1200 & 3000 & 0.35 \\
Base & 34 & 2000 & 5000 & 0.2 \\
Subbase & 20 & 1000 & 2500 & 0.3 \\
Subgrade & 200 & 80 & 80 & 0.4 \\
Natural soil & - & 80 & 80 & - \\
\hline
\end{tabular}

responses. In multilayered elastic theory the circular uniform distributed load is usually used to simulate tire-pavement contact pressure, which is suitable for small traffic volume, low load, and slow speeds. However, as tire inflation pressure and/or load increase, the contact area is drifting away from circular shape and the pressure distribution is no more uniform. Tire inflation pressure can vary from $0.6 \mathrm{MPa}$ to $1.3 \mathrm{MPa}[16]$. In China the standard tire inflation pressure is $0.7 \mathrm{MPa}$, under which the assumption of circular uniform distributed contact pressure is defined. However, when heavy loads, such as trucks, travel on the pavement, the contact areas behave as elliptical, even rectangular shapes, especially for heavy trucks with rigid tires. An empirical equation was used to calculate $L_{x}(1)$, and the contact areas of heavy truck tires were shown in Figure 2. Consider

$$
L_{x}=\frac{W g}{2.16 P}
$$

where $W$-mass, kg; $g$-acceleration of gravity, $\mathrm{m} / \mathrm{sec}^{2} ; P$-tire inflation pressure, $\mathrm{Pa}$.

The most common trucks travelling on highways in China are Dongfeng trucks with single tire on the front axle and dual tires on the rear axle. A typical type of Dongfeng trucks is called EQ1168G1 (Figure 2), with standard load of $16000 \mathrm{~kg}$, but could overload as much as $25000 \mathrm{~kg}$. 

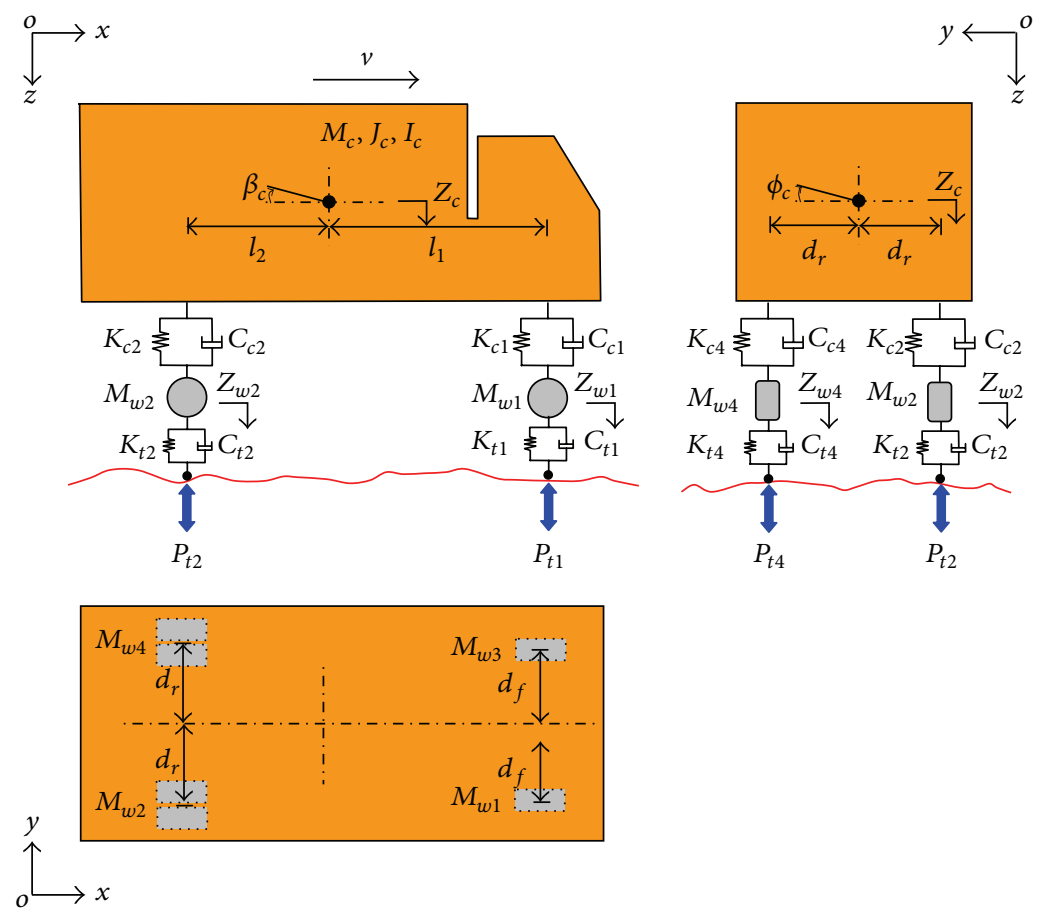

FIGURE 2: Moving dynamic simplified analysis model of two axles heavy truck (EQ1168G1).

\section{Development of 3D Direct Vehicle-Pavement Coupling Dynamic Model}

4.1. Vehicle Dynamic Model. A vehicle dynamic model based on EQ1168G1 with a $0.7 \mathrm{MPa}$ tire inflation pressure and $25000 \mathrm{~kg}$ load was developed utilizing multibody system dynamics, as shown in Figure 2. Symbols in Figure 2 are defined as follows:

$M_{c}=$ the total mass of truck, $\mathrm{kg} ;$

$J_{c}=$ pitching inertia of lorry body, $\mathrm{Nm}^{2}$;

$I_{c}=$ roll inertia, $\mathrm{Nm}^{2}$;

$Z_{c}=$ vertical displacement of lorry body, $\mathrm{m}$;

$\beta_{c}=$ pitching displacement of lorry body, $\mathrm{m}$;

$\phi_{c}=$ roll displacement of lorry body, rad;

$K_{c i}=$ stiffness coefficient of leaf spring, N/m;

$C_{c i}=$ damping coefficient of leaf spring, Ns/m;

$M_{w i}=$ mass of wheel, $\mathrm{kg}$;

$Z_{w i}=$ vertical displacement of wheel mass center, $\mathrm{m}$;

$K_{t i}=$ stiffness of tire, $\mathrm{N} / \mathrm{m}$;

$C_{t i}=$ damping of tire, $\mathrm{Ns} / \mathrm{m}$;

$q_{w i}=$ roughness of pavement surface under the mass center of tire, $\mathrm{m}$;

$l_{i}=$ horizontal distance between each axle to the mass center of lorry body, m;

$d_{f}, d_{r}=1 / 2$ distance between mass centers of left and right tires in front axle, and rear axle respectively, m;
$P_{t i}=$ equivalent tire-pavement vertical contact pressure, $\mathrm{Pa}$.

According to D'Alembert principle, the governing equation for vertical displacement of lorry body was shown in (2):

$$
\begin{aligned}
& M_{c} \ddot{Z}_{c}+C_{c 1}\left[\left(\dot{Z}_{c}+l_{1} \dot{\beta}_{c}+d_{f} \dot{\phi}_{c}\right)-\dot{Z}_{w 1}\right] \\
& +K_{c 1}\left[\left(Z_{c}+l_{1} \beta_{c}+d_{f} \phi_{c}\right)-Z_{w 1}\right] \\
& +C_{c 2}\left[\left(\dot{Z}_{c}-l_{2} \dot{\beta}_{c}+d_{r} \dot{\phi}_{c}\right)-\dot{Z}_{w 2}\right] \\
& +K_{c 2}\left[\left(Z_{c}-l_{2} \beta_{c}+d_{r} \phi_{c}\right)-Z_{w 2}\right] \\
& +C_{c 3}\left[\left(\dot{Z}_{c}+l_{1} \dot{\beta}_{c}-d_{f} \dot{\phi}_{c}\right)-\dot{Z}_{w 3}\right] \\
& +K_{c 3}\left[\left(Z_{c}+l_{1} \beta_{c}-d_{f} \phi_{c}\right)-Z_{w 3}\right] \\
& +C_{c 4}\left[\left(\dot{Z}_{c}-l_{2} \dot{\beta}_{c}-d_{r} \dot{\phi}_{c}\right)-\dot{Z}_{w 4}\right] \\
& +K_{c 4}\left[\left(Z_{c}-l_{2} \beta_{c}-d_{r} \phi_{c}\right)-Z_{w 4}\right]=M_{c} g .
\end{aligned}
$$

When the coupling effect between tire and pavement is considered, the governing equation can be written as (3) for each wheel:

$$
\begin{array}{r}
M_{w i} \ddot{Z}_{w i}-C_{c i}\left[\left(\dot{Z}_{c}+l_{i} \dot{\beta}_{c}+d_{f} \dot{\phi}_{c}\right)-\dot{Z}_{w i}\right] \\
-K_{c i}\left[\left(Z_{c}+l_{i} \beta_{c}+d_{f} \phi_{c}\right)-Z_{w i}\right]+P_{t i}=M_{w i} g \\
i=1,2,3,4 .
\end{array}
$$

In the proposed vehicle model, the body is $900 \mathrm{~cm}$ long, and the distance between front and rear suspension 
TABLE 2: Dimensional values and boundary conditions of finite models.

\begin{tabular}{|c|c|c|c|}
\hline \multirow{2}{*}{ Models } & \multirow{2}{*}{$\begin{array}{l}\text { Static response } \\
\text { Model } 1\end{array}$} & \multicolumn{2}{|c|}{ Dynamic response } \\
\hline & & Model 2 & Model 3 \\
\hline Dimension (depth $\times$ width $\times$ length) & $2.69 \mathrm{~m} \times 10 \mathrm{~m} \times 15 \mathrm{~m}$ & $2.69 \mathrm{~m} \times 5 \mathrm{~m} \times 80 \mathrm{~m}$ & $2.69 \mathrm{~m} \times 10 \mathrm{~m} \times 200 \mathrm{~m}$ \\
\hline Total reduced element amount & 59136 & 1116600 & 639600 \\
\hline Element amount for infinite foundation & 2464 & 47600 & 15600 \\
\hline \multicolumn{4}{|l|}{ Boundary conditions } \\
\hline Lateral sides & $\begin{array}{l}\text { Lateral displacements are } \\
\text { fixed }\end{array}$ & $\begin{array}{l}\text { Lateral displacements are } \\
\text { fixed }\end{array}$ & $\begin{array}{l}\text { Lateral displacements are } \\
\text { fixed }\end{array}$ \\
\hline Longitudinal sides & $\begin{array}{l}\text { Longitudinal displacements } \\
\text { are fixed }\end{array}$ & $\begin{array}{l}\text { Longitudinal displacements } \\
\text { are fixed }\end{array}$ & $\begin{array}{l}\text { Longitudinal displacements } \\
\text { are fixed }\end{array}$ \\
\hline Bottom & $\begin{array}{l}\text { Vertical displacements are } \\
\text { fixed }\end{array}$ & $\begin{array}{l}\text { Vertical displacements are } \\
\text { fixed }\end{array}$ & $\begin{array}{l}\text { Vertical displacements are } \\
\text { fixed }\end{array}$ \\
\hline
\end{tabular}

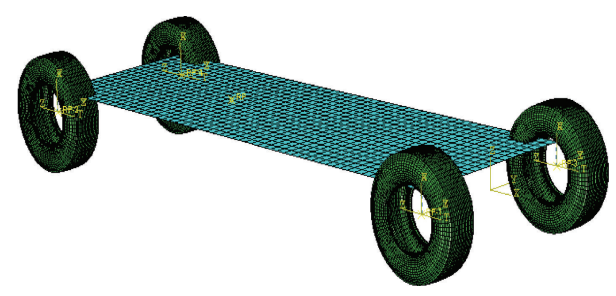

FIGURE 3: Finite model of vehicle with radial wide base tires.

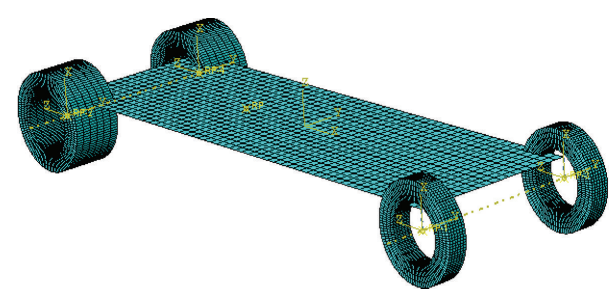

FIGURE 4: Equivalent tire-lorry body finite model.

is $560 \mathrm{~cm}$. The mass center of the body is located at the point $1 / 3$ of the axle distance away from the rear axle. The parameters in spring-damping system cannot be obtained from test directly. Wide base radial tires are prevailing among heavy trucks. When components of this kind of tire are simulated directly, rubber should be participated into about 15000 elements and close wire requires very tiny meshes, as shown in Figure 3, which would jeopardize the computation efficiency. Therefore, based on (1), an equivalent tire model was developed, as shown in Figure 4. The tire was assumed as isotropic elastic body with a $200 \mathrm{MPa}$ stiffness coefficient, which was participated into only 12584 three-dimensional 8 nodes reduced elements. Four spring-damping systems $(2 \mathrm{MPa}, \mathrm{Ns} / \mathrm{m})$ were utilized to simulate the connection between the lorry body and tires [23].

4.2. Pavement Models. Three pavement models were developed, as shown in Table 2. In static analysis, Newton iteration implicit algorithm is adopted. The global stiffness matrix is required, and its reverse matrix should be calculated. Soaring demand on memory would occur when element amount

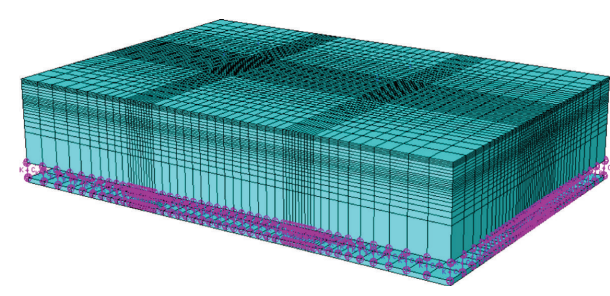

FIGURE 5: Pavement finite model in static analysis (Model 1).

increases. Therefore, a relative small sized pavement model (named Model 1), as shown in Figure 5, was developed to conduct vehicle-pavement coupling static response.

In dynamic analysis, central difference explicit algorithm was utilized to obtain the global stiffness matrix directly, which requires much less memory than the implicit algorithm in static analysis. Therefore, total amount of element can be larger in dynamic analysis. In order to simulate responses in a specific point under contact area, pavement structure beneath contact area was participated very densely, and a python program was developed to produce transitional elements, as shown in Figure 6(b). This model was named Model 2.

Another pavement model, named Model 3 (Figure 7), was developed in larger dimensions to fully reflect dynamic pavement responses due to the moving load. No transitional elements were used in Model 3. A rigid road surface was introduced in front of pavement structure in longitudinal direction, so that a steady state could be kept for the moving vehicle when it moved onto the pavement structure.

\section{Validation of the Developed Models and Analysis on Pavement Response}

5.1. Static Analysis. In static analysis, displacement fields and stress fields were studied and compared with analytical solution from layered elastic system. Figure 8 showed the pavement surface deflection nephogram under static vehicle load. The maximum deflection located at each rear tire center was about $0.5 \mathrm{~mm}$. The maximum deflection calculated from layered elastic system occurred in the same points and was 


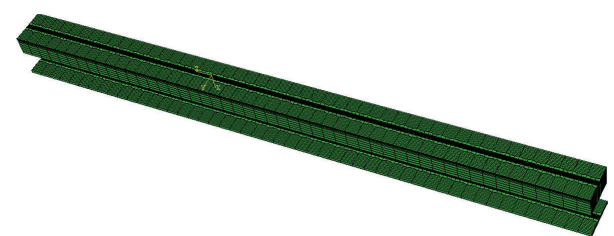

(a) Global sketch

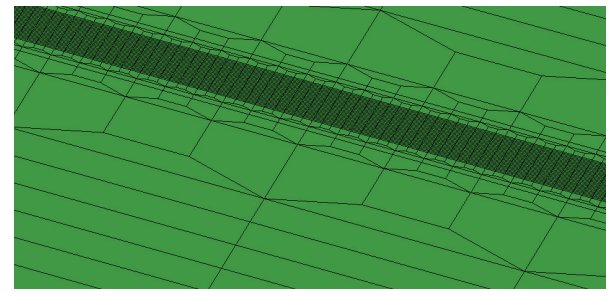

(b) Partial enlarged detail

Figure 6: Pavement finite model with densely participated elements under contact area (Model 2).

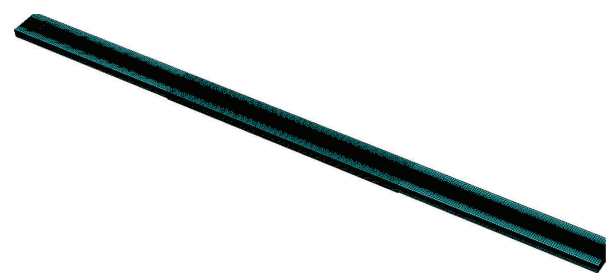

(a) Global sketch

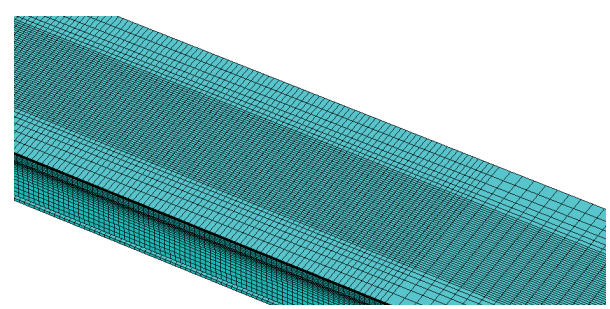

(b) Partial enlarged detail

FIgURE 7: Pavement finite model for global pavement dynamic response (Model 3).

about $0.48 \mathrm{~mm}, 4 \%$ lower than the simulated result. Therefore, the static model is validated. The error would decrease when the mesh density increases. Additionally, a single load and infinite boundary in layered elastic system also vary from load and boundary conditions in the static finite element model. It was found that the pavement deflection due to vehicle load diminished quickly and the total influential area is no more than 3 times the contact area.

The contact pressure distribution in static analysis was shown in Figure 9. The main part of the contact area had a $0.7 \mathrm{MPa}$ pressure, except the center with $2 \mathrm{MPa}$ pressure, which looks like an upside down bowl.

5.2. Dynamic Analysis. In the dynamic analysis, the vehicle was simulated to travel at $60 \mathrm{~km} / \mathrm{h}$, and dynamic responses of pavement structure were calculated utilizing central difference explicit algorithm. The pavement and load conditions

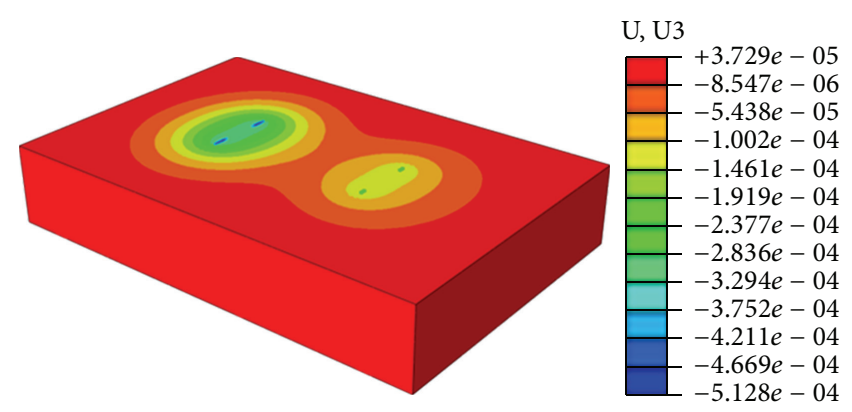

FIGURE 8: Deflection nephogram in static analysis.

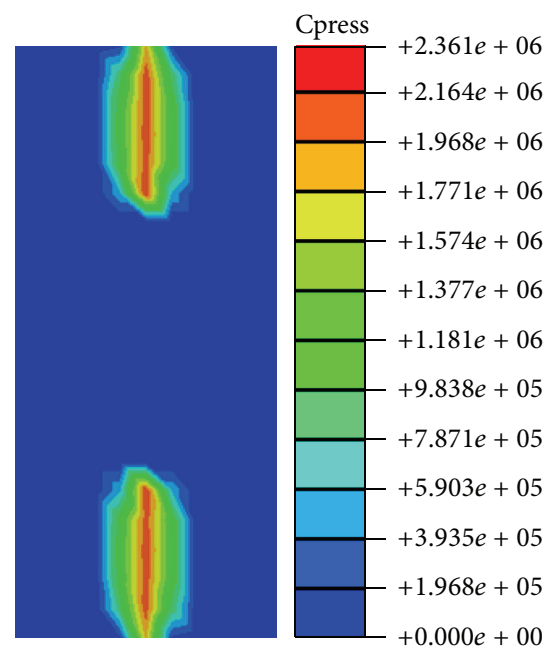

FIGURE 9: Contact pressure distribution in static analysis.

from implicit algorithm in static analysis were input into dynamic model as initial conditions. Reciprocal difference method on explicit dynamic and implicit static was introduced in such analysis. In order to evaluate the validity and accuracy of the dynamic model, the vertical compressive strain time-history curve of a point located on the surface of base was shown in Figure 10(a). This curve shared similar longitude and change trend with the measured curve in the similar pavement structure with similar vehicle and speed [24]. Therefore, the dynamic model developed was proved to be valid.

Figure 11 showed the vertical displacement time-history of a point on the pavement surface. It was found that before the travel load arrived at this point, a small upward displacement occurred. Based on the stress wave theory and Hertz contact model, this displacement is because of the stress wave spread and the shear behavior of asphalt pavement. The first and the second longitudes in the timehistory curve reflect the front and rear wheels moving over the analysis point, respectively. During the high speed time, the vertical displacement due to the front wheel did not diminish when the rear wheel arrived, and overlap occurred. This overlap increases when the traffic speeds up, which sufficiently explains why high speed traffic has a stronger effect on the pavement displacement than low speed traffic. 


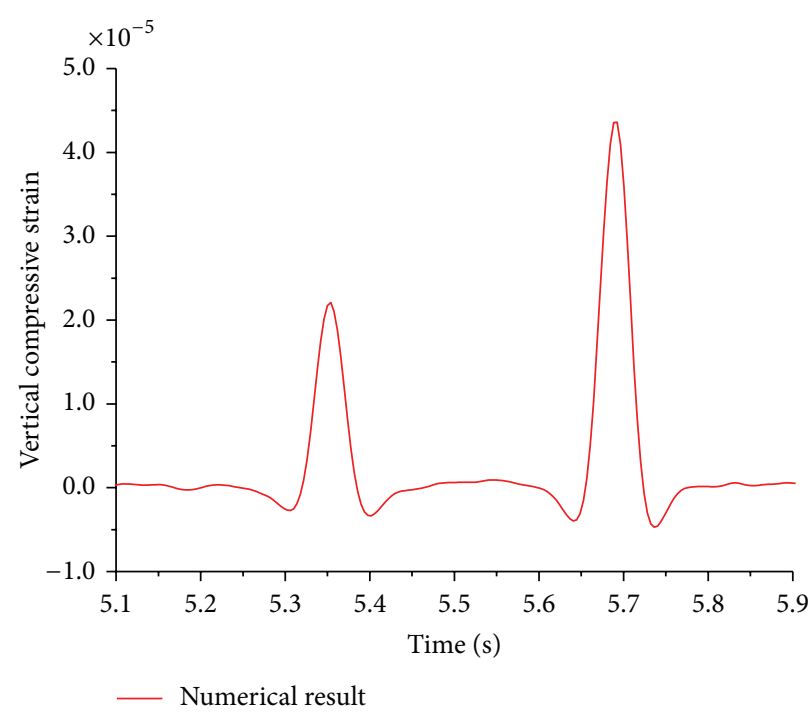

(a) Simulated time-history curve

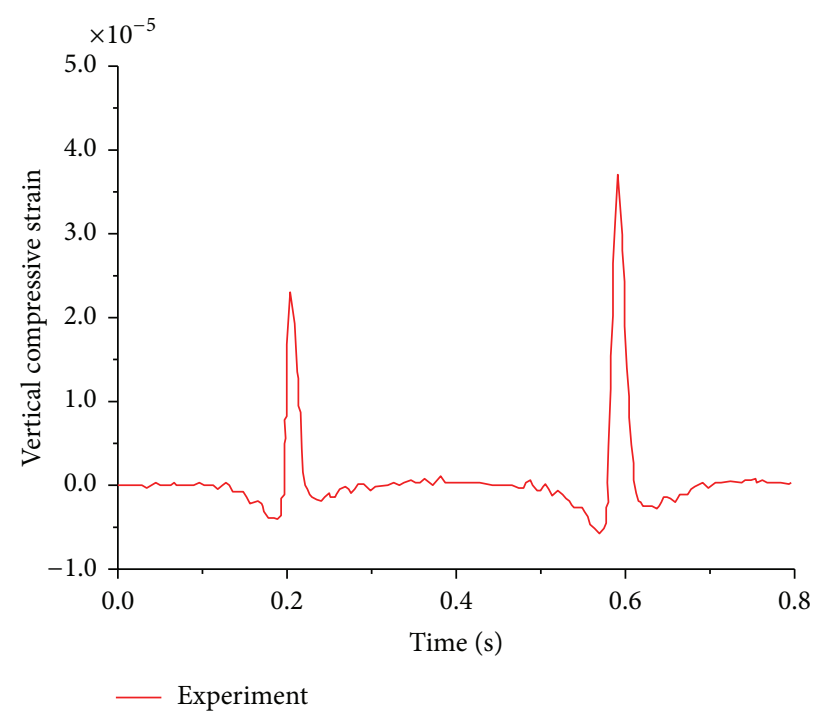

(b) Measured time-history curve on similar pavement

FIGURE 10: Comparison between simulated time-history curve and the measured one on vertical compressive strain of a point located on base surface.

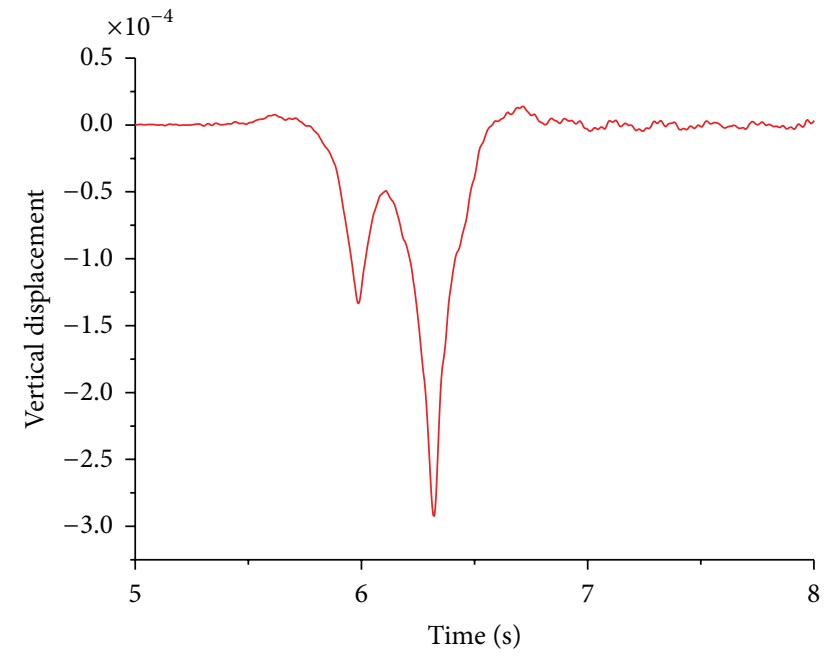

FIGURE 11: Vertical displacement time-history curve of a point on the pavement surface.

However, when vertical compressive strain was considered, as shown in Figure 12, no overlap occurred. This phenomenon is different from the vertical displacement time-history curve. The effects of dynamic loads on vertical compressive strain were found to be slighter than on vertical displacement on the pavement surface.

In order to study the influence of travel load on pavement structure shear behavior, the shear stress fields on the pavement surface and on the top of base were obtained from dynamic analysis on Model 3, as shown in Figures 13 and 14, respectively. The longitudinal tangential stress in the contact area on the pavement surface distributed almost evenly around $0.08 \mathrm{MPa}$, as shown in Figure 13. However,

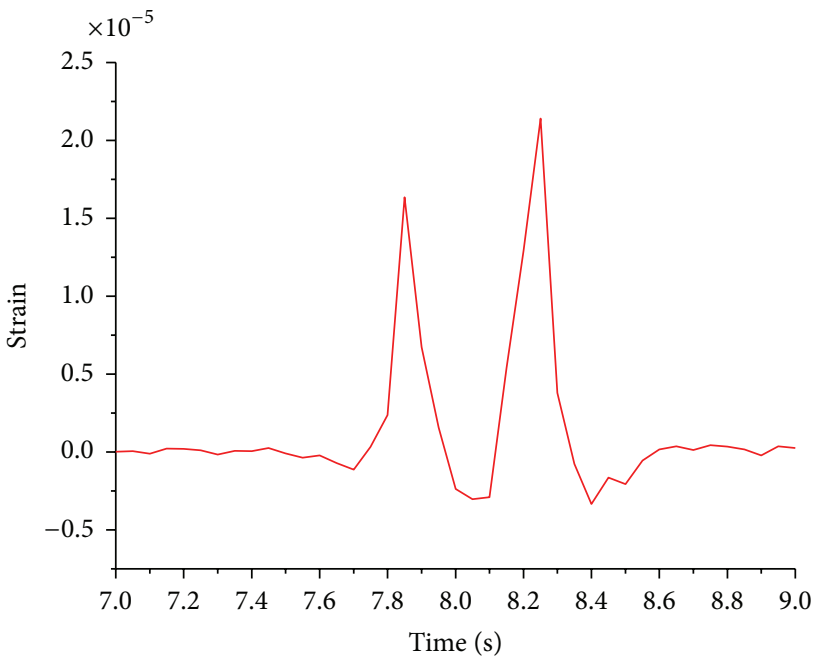

FIGURE 12: Vertical compressive time-history curve of a point on the pavement surface.

the longitudinal tangential stress on the top of base varied a lot with a $0.12 \mathrm{MPa}$ under the rear tire, as shown in Figure 14. Stress discontinuity was observed between the loading area and its adjacent area where vehicle just passed, with a maximum longitudinal tangential stress $-0.18 \mathrm{MPa}$. This is because instant unloading occurred after the vehicle passed over the pavement. It is indicated that since the influences of dynamic loads and static loads on asphalt pavement responses vary significantly, the dynamic effects should be fully considered when analyzing asphalt pavement responses.

Due to inertia force, phugoid motion can be observed on a moving vehicle, as shown in Figure 15, even if no roughness was introduced onto the pavement surface. Because of 


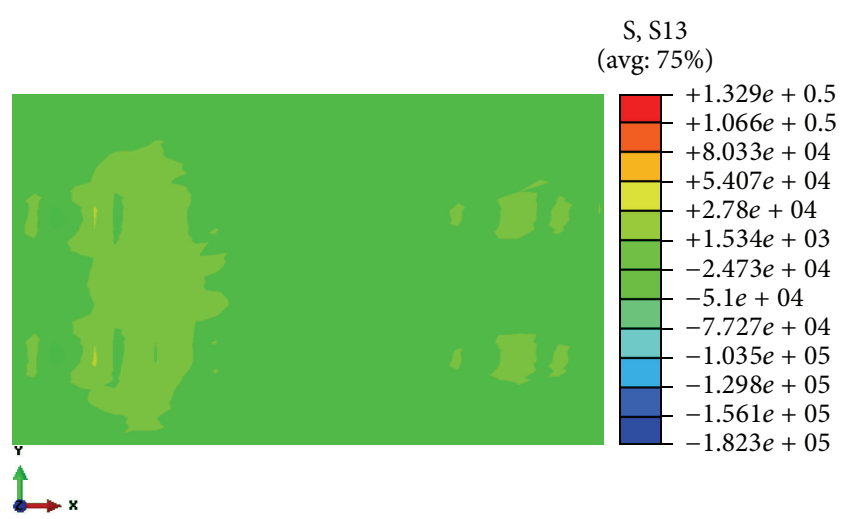

FIGURE 13: Shear stress field on the pavement surface (S13).

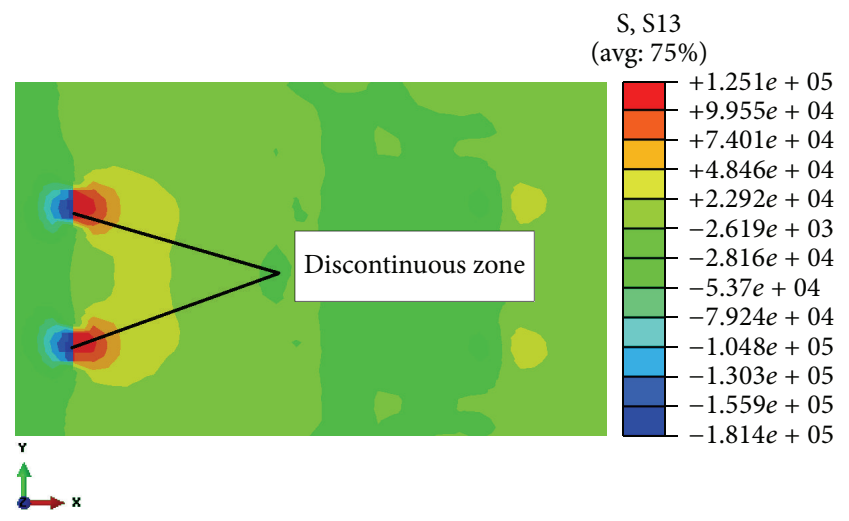

FIGURE 14: Shear stress field on the top of base (S13).

the weight load of vehicle, a deflection will occur on the pavement surface and the lorry body would fall down. Then vibration starts because of the inertia force of the lorry body. The shifting range of the lorry body mass center was no more than $5 \mathrm{~mm}$, and the acceleration of it was less than the gravitational acceleration (Figure 16), which is acceptable for human body.

\section{Conclusions}

Based on static equilibrium and dynamic D'Alembert principle, the direct vehicle-pavement coupling static and dynamic finite models were developed, and asphalt pavement responses were analyzed and validated by analytical solutions in elastic layered system and measured data. Several conclusions can be drawn as follows.

(i) The developed 3D direct vehicle-pavement coupling dynamic model was validated to be an effective tool to consider the vehicle-pavement coupling effects on asphalt pavement responses and vehicle vibration.

(ii) The proposed equivalent tire model only contains $25 \%$ elements of normal radial wide base tire model and improves the simulation efficiency while ensuring the accuracy. With transitional elements introduced

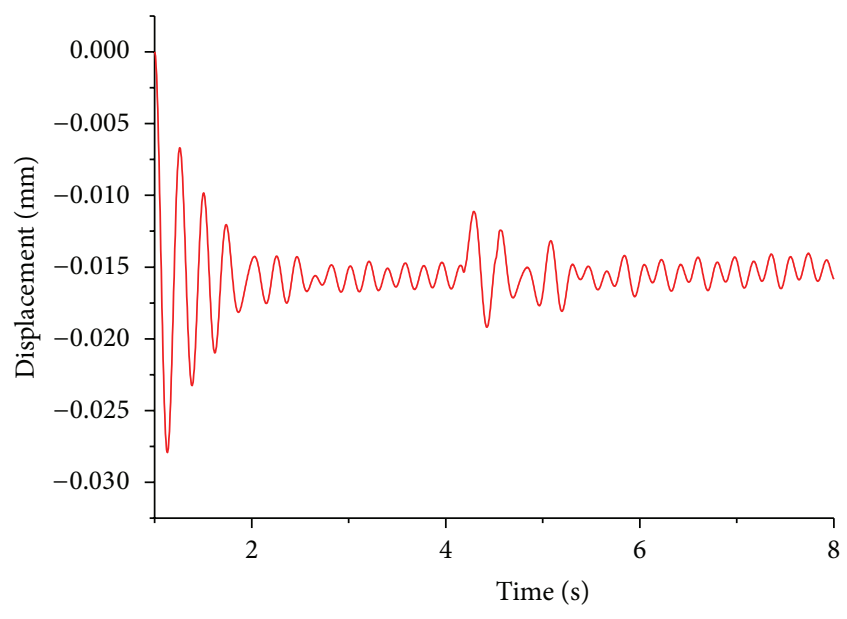

FIGURE 15: Vertical time-history displacement curve of vehicle mass center during moving.

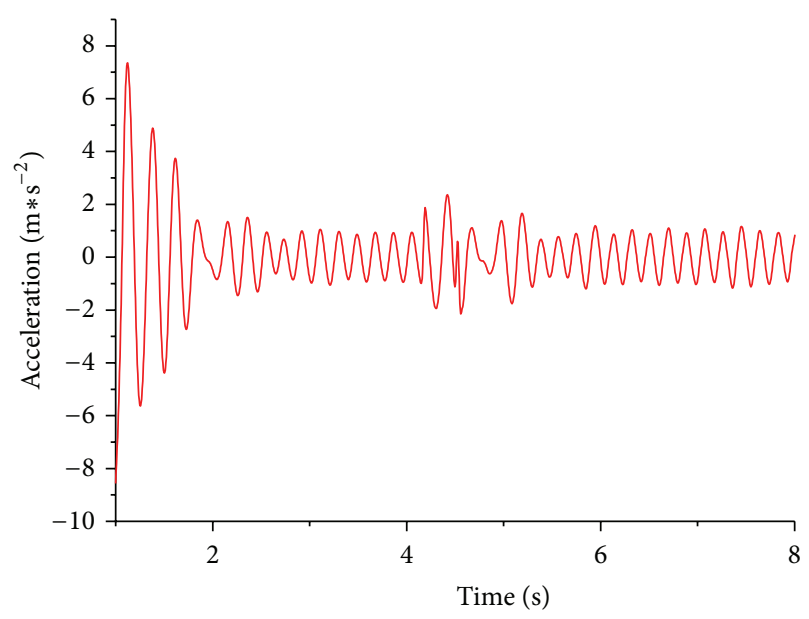

Figure 16: Vehicle mass center acceleration time-history curve.

on the boundary of tire-pavement contact area, the developed dynamic model contains much less elements and can be run on personal computers.

(iii) Overlapping occurs on the pavement surface deflection under a moving vehicle, and this phenomenon enhances while the vehicle speed increases. No obvious overlapping effect was observed on the vertical strain on the pavement surface.

(iv) For the longitudinal tangential stress on the top of base, discontinuity exists between the point under moving load and the point the moving load just passed. Therefore, the developed 3D direct vehiclepavement coupling dynamic model successfully reflects the shear effect of moving loads on asphalt pavement.

(v) Vibration occurs on vehicle even if there is no roughness introduced onto pavement surface. 


\section{Acknowledgments}

The work described in this paper was supported by research project funded by the China Ministry of Communications (Project no. 19672016) and Project 51078111 of the National Science Foundation of China.

\section{References}

[1] S. Pirabarooban, Modeling of rutting in asphalt mixes using ABAQUS [M.S. thesis], University of Oklahoma, Norman, Oklahoma, 2002.

[2] J. Cole and J. Huth, "Stresses produced in a half plane by moving loads," Journal of Application Mechanics, vol. 25, no. 12, pp. 433436, 1958.

[3] M. L. Baron, H. H. Bleich, and J. P. Wright, "Ground shock due to raleigh waves from sonic bombs," Journal of Engineering Mechanics, vol. 93, no. 5, pp. 137-162, 1967.

[4] J. T. Kenney, "Steady-state vibration of beam on elastic foundation for moving load," Journal of Application Mechanics, vol. 21, no. 4, pp. 359-364, 1954.

[5] T. Hanazato, K. Ugai, M. Mori, and R. Sakaguchi, "Threedimensional analysis of traffic-induced ground vibrations," Journal of Geotechnical Engineering, vol. 117, no. 8, pp. 1133-1151, 1991.

[6] D. V. Jones and M. Petyt, "Ground vibration in the vcinity of a rectangular load on a half-space," Journal of Sound and Vibration, vol. 166, no. 1, pp. 141-159, 1993.

[7] D. V. Jones, D. le Houedec, and M. Petyt, "Ground vibrations due to a rectangular harmonic load," Journal of Sound and Vibration, vol. 212, no. 1, pp. 61-74, 1998.

[8] V. V. Krylov, "Vibrational impact of high-speed trains. I. Effect of track dynamics," Journal of the Acoustical Society of America, vol. 100, no. 5, pp. 3121-3134, 1996.

[9] B. Huang, L. N. Mohammad, and M. Rasoulian, "Three dimensional numerical simulation of asphalt pavement at Louisiana accelerated loading facility.", Transportation Research Record, 1764, Transportation Research Board, Washington, DC, USA, 2001.

[10] I. Abu Alshaikh, D. Turhan, and Y. Mengi, "Two-dimensional transient wave propagation in viscoelastic layered media," Journal of Sound and Vibration, vol. 244, no. 5, pp. 837-858, 2001.

[11] G. Lefeuve-Mesgouez, D. le Houédec, and A. T. Peplow, "Ground vibration in the vicinity of a high-speed moving harmonic strip load," Journal of Sound and Vibration, vol. 231, no. 5, pp. 1289-1309, 2000.

[12] H. Hao and T. C. Ang, "Analytical modeling of traffic-induced ground vibration," Journal of Engineering Mechanics, vol. 21, no. 8, pp. 135-148, 1998.

[13] X. Sheng, C. J. C. Jones, and M. Petyt, "Ground vibration generated by a load moving along a railway track," Journal of Sound and Vibration, vol. 228, no. 1, pp. 129-156, 1999.

[14] X. Sheng, C. J. C. Jones, and M. Petyt, "Ground vibration generated by a harmonic load acting on a railway track," Journal of Sound and Vibration, vol. 225, no. 1, pp. 3-28, 1999.

[15] S. Lu and D. Xuejun, "Dynamic analysis to infinite beam under a moving line load with uniform velocity," Applied Mathematics and Mechanics, vol. 19, no. 4, pp. 367-373, 1998.

[16] P. Lv, R. Tian, and X. Liu, "Dynamic response solution in transient state of viscoelastic road under moving load and its application," Journal of Engineering Mechanics, vol. 136, no. 2, pp. 168-173, 2010.

[17] S. Zaghloul and T. White, "Use of a three-dimensional dynamic finite element program for analysis of flexible pavement," Transportation Research Record 1388, TRB, National Research Council, Washington, DC, USA, 1993.

[18] B. Alabi, "A parametric study on some aspects of ground-borne vibrations due to rail traffic," Journal of Sound and Vibration, vol. 153, no. 1, pp. 77-87, 1992.

[19] B. Saad, H. Mitri, and H. Poorooshasb, “Three-dimensional dynamic analysis of flexible conventional pavement foundation," Journal of Transportation Engineering, vol. 131, no. 6, pp. 460-469, 2005.

[20] C.-W. Huang, R. K. Abu Al-Rub, E. A. Masad, and D. N. Little, "Three-dimensional simulations of asphalt pavement permanent deformation using a nonlinear viscoelastic and viscoplastic model," Journal of Materials in Civil Engineering, vol. 23, no. 1, pp. 56-68, 2011.

[21] F. Zhang, D.-C. Feng, X.-Z. Ling, Z.-Y. Wang, and Z.-Y. Zhu, "Vertical dynamical analysis model of heavy vehicle-pavementsubgrade during spring-thawing period," China Journal of Highway and Transport, vol. 24, no. 4, pp. 7-14, 2011.

[22] Applied Research Associates, "Guide for mechanistic-empirical pavement design," NCHRP Project 1-37A, Transpiration Research Board, Washington, DC, USA, 2004.

[23] S. Li, Investigation on dynamics of heavy vehicle-pavementfoundation coupled system [Dissertation], Beijing Jiaotong University, Beijing, China, 2008.

[24] X. Deng and L. Sun, System Dynamics of Vehicle-Ground Structures, People's Transportation Publishing House, Beijing, China, 2000. 


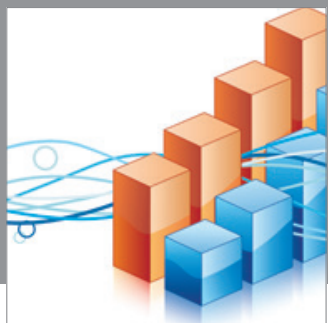

Advances in

Operations Research

mansans

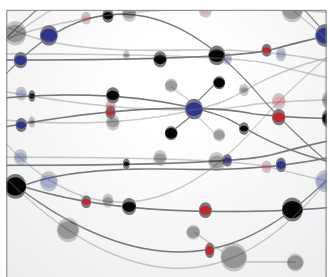

The Scientific World Journal
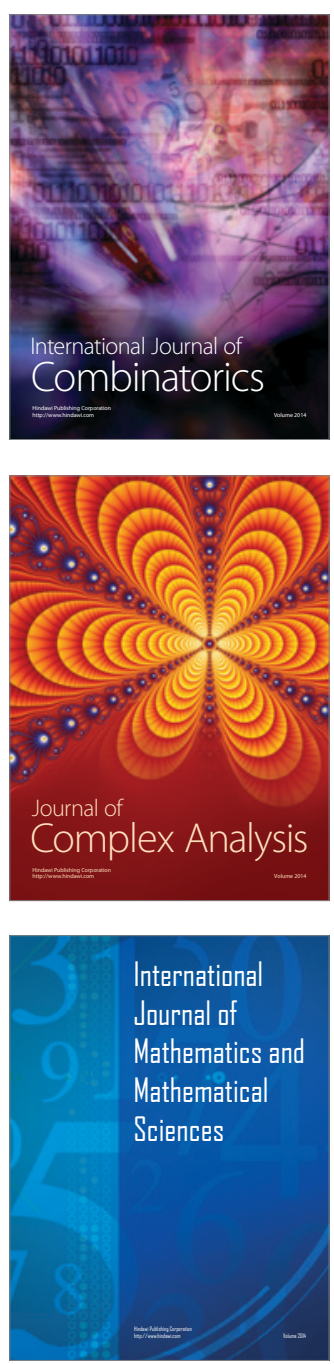
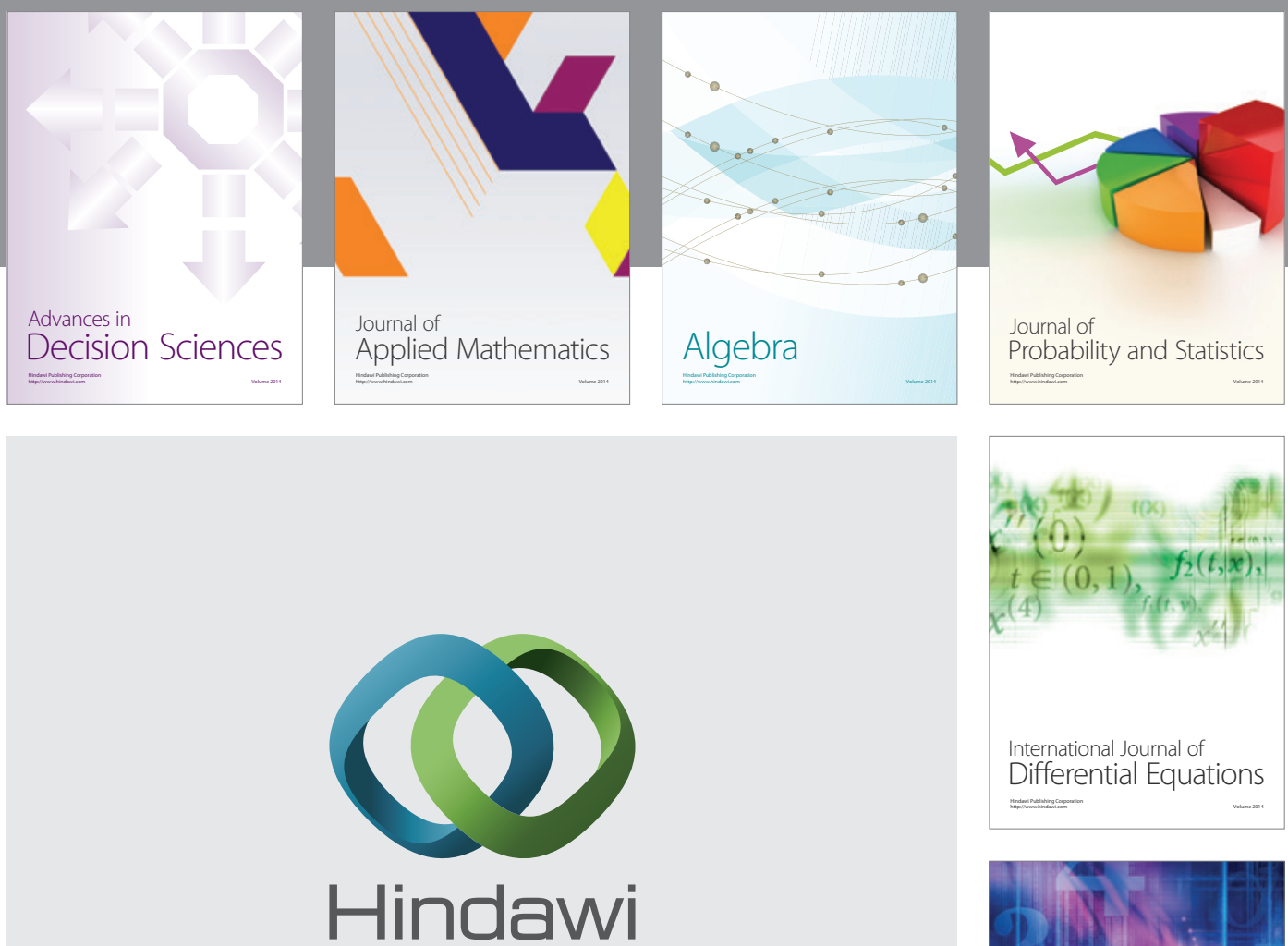

Submit your manuscripts at http://www.hindawi.com
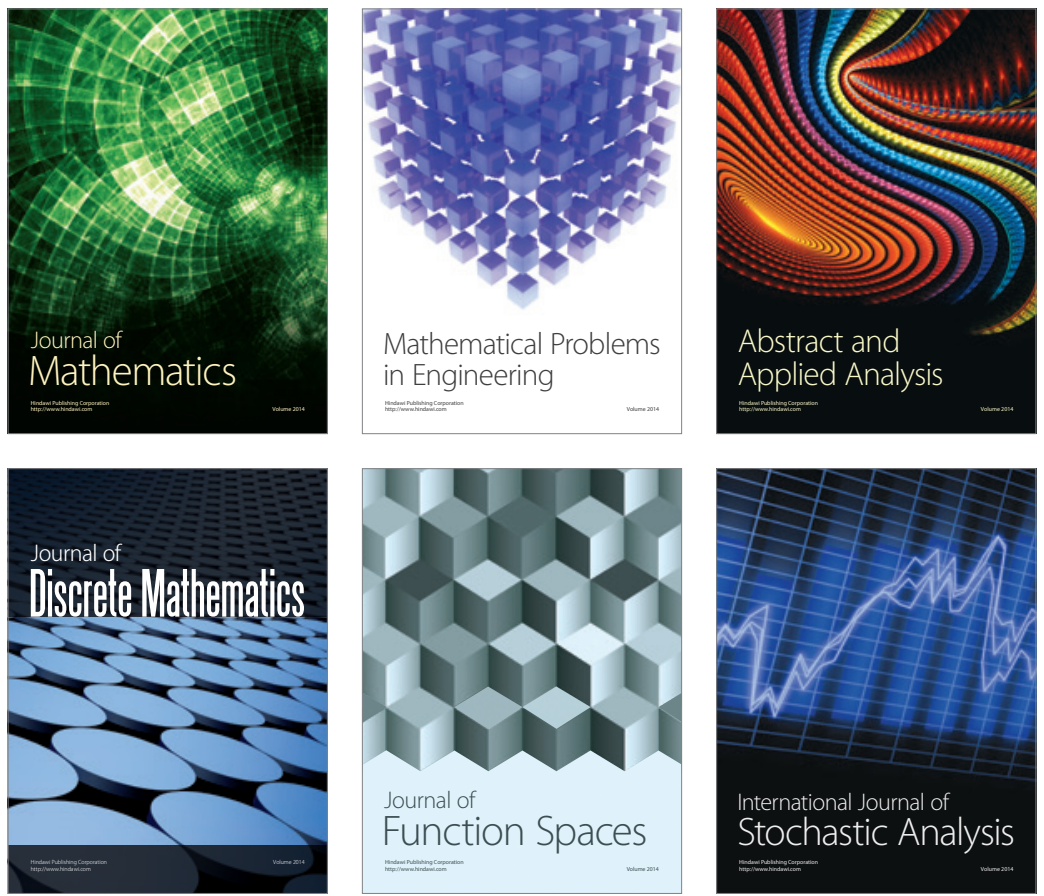

Journal of

Function Spaces

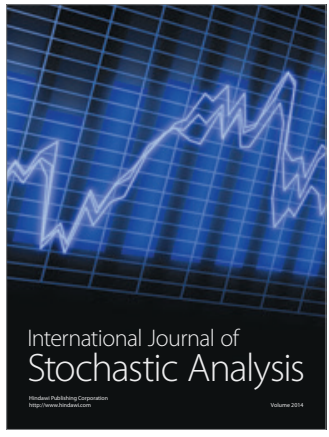

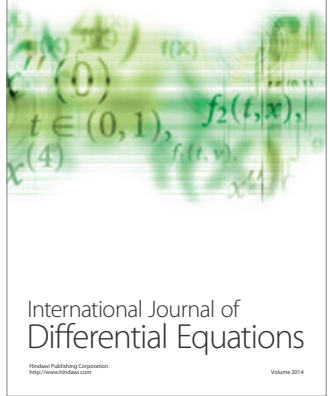
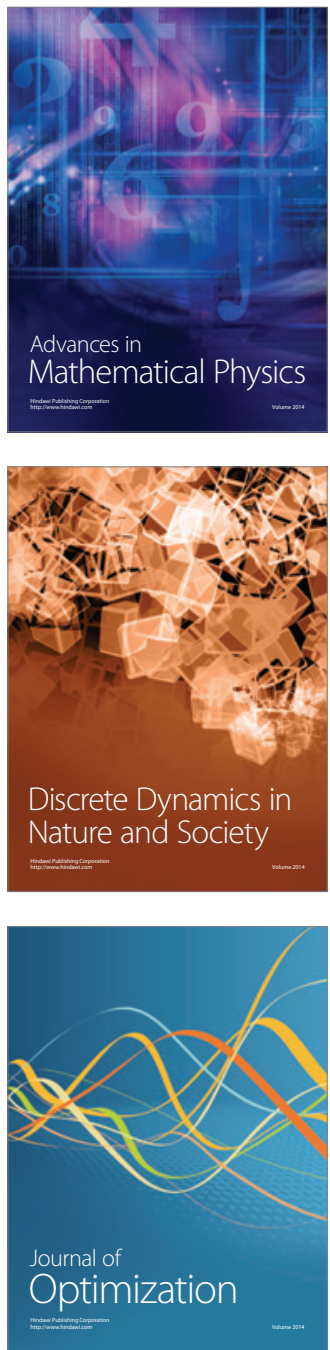